Article

\title{
Determinants of the Relationship of Medical Service Entities in the Virtual Environment
}

\author{
Justyna Matysiewicz * and Sławomir Smyczek \\ Department of Consumer Research, University of Economics in Katowice, 40-287 Katowice, Poland; \\ slawomir.smyczek@ue.katowice.pl \\ * Correspondence: justyna.matysiewicz@uekat.pl
}

Received: 27 May 2020; Accepted: 14 August 2020; Published: 21 September 2020

\begin{abstract}
Introducing new technologies to the healthcare market provides unique opportunities for implementing a powerful framework of resources, tools, and applications that can revolutionize the ways in which medical units interact with their patients, as well as help deliver and manage medical services. The Internet of Services, as a new concept of Internet evaluation, depends not only on technological solutions but also on service innovations in the field of new value propositions where a patient-centered model is needed. Such a model would consider patient preferences, values, and the need for information as the leading characteristics of care. Patient and medical unit engagement is an essential prerequisite for the new value proposition development process. In this paper, we focus on the identification and analysis of the determinants responsible for the mutual engagement of patients and medical units. The purpose of this study was to identify and describe a relational model for the virtual healthcare service market. This study adopted a quantitative survey approach. The questionnaire was based on a three-factor model of consumer behavior, considering motivation, capacity, and opportunities. The relationships between patients and healthcare organizations will develop on the condition that the patients are properly motivated and have adequate abilities to become engaged in the relationships with health care providers.
\end{abstract}

Keywords: service management 1; engagement determinates 2; patient-healthcare organization relationships

\section{Introduction}

The challenges facing healthcare systems in recent years have significantly influenced the business models of healthcare units. Demographic changes, globalization, and also the improvement of health technologies leading to better survival alongside with raising patient expectations all contributing to placing increasing pressure on available healthcare resources. The dominant model based on physician-centered care patterns has been questioned; although these patterns are gradually transforming, new patient-centered care has been slow to develop [1-5].

According to Lega and de Pietro [2], emerging trends are moving medical unit processes related to the needs of care processes and patients away from the traditional physician-centered approach. As for the patient-centered care, an individual's specific health needs and desired health outcomes are the driving force behind all healthcare decisions and quality measurements. Patients are treated as partners with their healthcare providers and the providers treat their patients not only from a medical perspective but also from the emotional, mental, spiritual, social, and financial ones [6].

Patient-centered care also creates pressures that are reshaping healthcare delivery approaches and care processes. Patients receive more information and are becoming increasingly aware of their medical situations, rights, and alternative treatments, while at the same time becoming more engaged. As Maravino stated, patients increasingly search for value in their healthcare purchases, which entails 
an optimal balance between quality and cost. The availability of electronic data makes it easier for prospective patients to receive better services using hospital rankings, physician grades, and other quality metrics [7].

The healthcare sector is built upon a foundation of relationships. As consumers of healthcare services, patients have relationships with both providers and their organizations. Patients' understanding of their treatment, alongside with playing an active role in their own care, can improve patient outcomes. However, without the qualities of interrelatedness and empathy, healthcare delivery is no more than a transactional service. Creating mutual relationships is the basis for improving treatment effectiveness.

Healthcare systems should admit that many patients want to be active participants and partners in their own care. Medical units need to understand that patients are more co-creators and co-managers of their own health when they receive health services, rather than passive recipients or receivers of services or advice. As emphasized by the UK National Clinical Guideline Centre, "health care professionals need to provide a context in which patients feel able to participate and to share decisions if they want to, thus ensuring a good experience for those patients" [8].

The use of information and communication technologies in the healthcare system is considered an important factor of patient engagement. The following study focuses on the identification and analysis of the determinants of mutual patient and medical unit engagement. The purpose of this study was to identify and describe a model of the relations of subjects in the healthcare services market. The proposed model examines the behavior of healthcare organization managers from a relationship perspective and can significantly develop our understanding of the complex relations between healthcare organizations and their patients in a virtual environment.

\section{Service Innovation and Value Proposition}

By implementing a patient-centered model, medical units are increasingly seeking consumer engagement and participation in their services. Under the adoption of a customer engagement perspective, patients are no longer viewed as passive recipients of medical services but increasingly as proactive participants in interactive, value-generating co-creation processes [9]. Vargo and Lusch developed a type of business logic around their service concept known as service-dominant logic (SDL), for which ten foundational premises were described. Each of these premises refers to a specific view on economic activities in general, interpreting every economy activity as a manifestation of a service [10]. SDL can be perceived as the theoretical background of the emerging field of service science and its research [11-13].

Soriano et al. [14] derived some important implications of the service concept to help understand the services themselves. The authors stated that "the fundamental and constitutive property of a service is neither its technical implementation nor its functionality but rather its value proposition". This value proposition can be defined as "the benefits customers can expect from your products and services" [15]. In the development of eHealth technologies, this proposition can be valuable [16] as it emphasizes important factors for improving technology and how this technology fits into practice [17]. Secondly, they also assumed that a service is a mutual and intrinsically relationship-based issue. A service is based on the relationship between the patient and medical units and is often mediated by technology. Value creation is relevant for both patients and medical units. According to the authors, "a service can only be sustainably successful if it creates both value for the user (otherwise it will fail on the market) and value for the provider (otherwise there is no way of sustaining the service over a longer time period)". Finally, the authors searched for the drivers for the future development of the Internet of Services, assuming that the basic driver is not technology, but rather the possibility of making new value propositions and creating new service systems. Thus, technology is mainly important because of the ability to create these new services (in particular, Internet and mobile technology). However, the role of technology is the role of an enabler, not the role of a driver [14].

The current industrial revolution has entailed changes in how people are educated, live, work, entertain, and travel, as well as how business and governments are changing to interact with the 
population. Swayne [18] noted that expanded Internet connectivity, high mobile adoption, and low-cost sensors are the main market drivers at present [19]. All these factors have led to the creation of "a dynamic global network infrastructure with self-configuring capabilities based on standard and interoperable communication protocols where physical and virtual 'things' have identities, physical attributes, and virtual personalities, use intelligent interfaces, and are seamlessly integrated into the information network", which is defined as the Internet of Things (IoT). This concept is still being evaluated. Researchers also refer to the idea of the "Future Internet", which relates to the concept of the Internet of Services [20]. In general, this concept is described as systematically using the Internet for new methods of value creation in the service sector [21].

As emphasized in the research by Soriano et al. [14], the successful development of a future Internet of Services will only partly depend on technological solutions. It will also depend on innovation in the field of new value propositions using technological solutions. Successful medical service innovation will have to focus on the value proposition and value creation processes and then build appropriate technological solutions to apply this concept [14]. The challenges facing healthcare systems in recent years have significantly influenced the business model of healthcare.

\section{Patients and Healthcare Unit Determinants of Mutual Relationship Engagement}

The concept of engagement has been examined in various disciplines, including psychology, organizational behavior, sociology, and political science [22]. From a customer behavior perspective, customer engagement is defined as "a psychological state that occurs by virtue of interactive customer experiences with a focal object in service relationships" [22]. Hollebeek et al. [23] emphasized that such engagement facilitates sales growth and provides superior competitive advantages and profitability [24]. Engaged customers, typically, display greater brand loyalty and satisfaction [25].

Patient engagement has attracted more attention from researchers in recent years. Shifting to a new patient-centered model, patients are considered to be active participants in shaping their own personal health outcomes $[26,27]$. Patient engagement refers to the process of building the capacity of patients, families, workplaces, and healthcare providers to facilitate and support the active involvement of patients in their own care, to enhance the safety, quality, and people-centeredness of healthcare service delivery [28].

Vahdat [29] showed that increasing patient involvement can be defined by the awareness of one's health status that helps individuals make better and more cost-effective choices. Moreover, higher patient engagement levels result in greater compliance and, ultimately, healthier individuals [30]. Highly engaged patients feel more in control and accept greater responsibility for their health.

It has thus become essential to understand the driving forces behind patient engagement. According to the research shown in [31], involvement is an antecedent to customer engagement. There are a several customer involvement definitions in the literature. Zaichkowsky [32] refered to the "perceived suitability of a person to an object based on the needs, values, and interests", while Guthrie and Kim [33] defined the concept as a "motivated situation that can be used to understand consumer attitudes toward the product or brand".

The patient-centered model, which represents an attempt to redesign the care delivery process around the needs of the patients by providing them with the most suitable settings according to their health conditions [34] (Figure 1), and the use of virtual communication tools and the delivery of medical services, are integrated elements. It has become necessary to study a relational model of the healthcare services market on the basis of determinants that condition the engagement of patients and medical units in building mutual relationships in the virtual environment. Diverse factors included in current market-subject relational models (e.g., the EBK and Nicosii models) make it more difficult for these analyses to explain the relational development mechanisms. Moreover, a good model is characterized, among other factors, by its simplicity.

Hence, it is necessary to present the determinants of the relations between the subjects of the health services market in a relatively simple, measurable, and pragmatic way. However, a dilemma 
arises: something that can be of utilitarian application (a very simple approach to the determinants) is not always acceptable from a scientific point of view. On the other hand, a considerable diversification of these determinants, although methodologically correct, can be useless from a utilitarian (pragmatic) point of view [35].

\section{Core principles}

Aim of the

health care

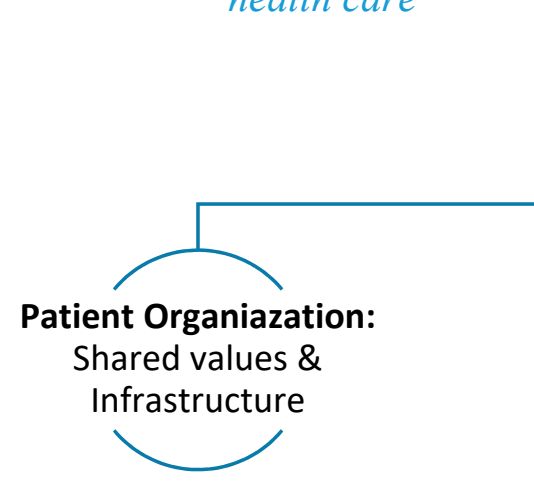

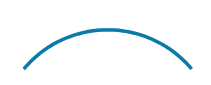

Engaged Patient
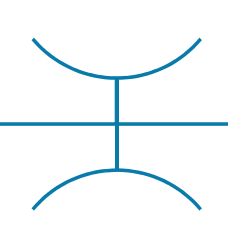

Team: Shared values \& Expectations

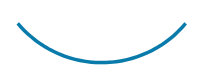

Benchmarks

Figure 1. Patient-centered model Source: G. Dennik-Champion, M.O. Schmelzer, Patient-centered team-based care in Wisconsin. A working conceptual model, Wisconsin Nurses Association, https: //wisconsinnurses.org/wp-content/uploads/2016/12/РCTBC-Narrative-Final.pdf.

\section{Three-Factor Relational Model of the Health Services Market in the Virtual Environment}

In the specialized literature, research can be found on the individual aspects of consumer-company relations, without considering, ceteris paribus, certain variables and interactions [36]. As we were particularly interested in the healthcare market, we decided to focus on the concept of a three-factor consumer behavior model (3F) [37]. Although this model was designed solely to explain consumers' market behavior, the universal characteristics of its construction allows for its application to medical units [35]. This model avoids the commonly used practice of a so-called summary of variables, i.e. including variables that are presented only on a general and abstract level. Often, the identification and explanation of the relations between subjects in various markets lead to limitations (both theoretical and operational) in the number of determinants, which constitute only a summary of a much larger number of more detailed variables [37].

We chose to use the approach of determination (definition of the influence over market-subject relations) with a narrow group of selected general factors, which allowed us to learn about the influence of these factors and the more detailed factors that determine these relations in practice. Consequently, through deeper analyses, one can achieve a methodologically correct, simple, and pragmatic approach. Such an approach has been already presented in the literature to describe and explain some selected aspects of customer-company relations [38] based on two main factors: motivation and abilities. D.J. MacInnes, C. Moorman, and B.J. Jaworski [39] proposed a model of three determinants that are responsible for shaping the attitudes of market subjects, distinguishing between motivation, opportunity, and ability (MOA model). This approach was further developed into a model of advertising message processing by Poiesh [40].

The above-mentioned models describe the information processing by market players during their entry into market relations with other entities. However, these models can also be more broadly used, e.g., for a complete explanation of a complicated phenomenon using a three-factor relational model based on motivation, abilities, and opportunities, which must be elaborated according to the following assumptions [35]: 
- Before making "a decision" about involvement in definite market relations, the subject must define their motivations and assess their abilities, as well as their external opportunities; it is assumed that this assessment requires minimum intellectual and time engagement on the part of the subject.

- Three main conditions exist for the relations to appear between entities: motivation to become engaged in a definite relation, the (perceived) abilities necessary to become engaged (e.g., knowledge, market experience, and (perceived) opportunities favorable for engagement). Motivation of a patient is connected, for example, to a need to be healthy or to external stimuli, such as promotional activities or informal information. Motivation of the medical unit relates to, e.g., the generation of larger profits. Abilities, in turn, are connected to, for example, a patient's intellectual predispositions, prior knowledge, and experience. The abilities of medical units correspond to their financial resources or available personnel and also include elements that are outside particular market participants. For the patient, these elements include streamlined procedures for medical service delivery, which can facilitate involvement in the relationship, and for medical units, an adequate level of patient knowledge. Opportunities are mainly related to the environment (favorable or not) in which the relations are being developed (market offers, market infrastructure, disturbances, etc.). Notably, the 3F model is based on the assumption that the determinants are prerequisites for the development of certain market relations. These conditions are insufficient since, for example, the absence of one component can be fully compensated for by the excess of another.

- In this model, it is assumed that all factors that practically affect the relations between market entities can be reduced to three determinants. This level of generality makes a more detailed analysis of the various determinants pointless.

- It is also assumed that the three main determinants can affect each other. For example, if the level of opportunities perceived by the patient is very low, then a high motivation for engagement in the relationship with a given medical unit is unlikely to emerge. If a medical unit, in turn, is insufficiently motivated to offer certain services for a given segment of patients, then neither a high level of opportunities perceived by the personnel nor market opportunities would be able to encourage the subject to become involved in the relations.

- A combination of determinants (motivation, opportunities, and abilities) can be examined with a high level of generality (the service, brand, etc.) or in a more detailed range (depending on the service, brand, etc.). Once a given market model is capable of considering various determinants, it becomes engaged in a given relation in the market.

- If there is no need for a more detailed analysis of the determinants responsible for the relations between market participants (a general definition of motivation, abilities, and opportunities), then it is possible to differentiate each variable [37].

Motivation is one of the essential drivers of individual behavior and performance and, consequently, is an integral component of patient engagement [41]. A motive exists only when a given subject (a patient or a medical unit representative) becomes aware of reaching a desired goal and engages in action-provoking decisions. Motives and behaviors constitute unity, motives, and goals that evoke some kind of feedback. On the one hand, motivation reveals the significance of goals and tasks; on the other hand, goals and tasks affect motivation. In this approach, the behavior of a healthcare market entity represents a factor that fosters the actions undertaken to develop relations with other entities [42].

Next to motivation, an important role in the $3 \mathrm{~F}$ model of entity relations is abilities. In a colloquial sense, abilities are described as talent, wisdom, acuity, and wit, where an able person is one who has the capacity and abilities to do something [43]. In the presented model, abilities are referred to as personal competencies and predispositions, as well as the intellectual and economic potential of patients and medical units that can help them become engaged in market relations. Thus, a patient's engagement with a certain medical unit will depend on his or her personality, perception, attitudes, preferences, speed of learning and remembering, degree of risk acceptance, and market novelties. Medical units 
with management and personnel featuring abilities such as experience, knowledge, internal resources (especially financial), information, or the acceptance of market novelties are at stake of not becoming engaged in definite market relations [35].

The last factor is represented by opportunities, which are often referred to as probability, chance, strength, predispositions, potential, and possibility [43]. In this model, opportunities are described as the favorable or unfavorable conditions for a subject to become engaged in definite relations. Hence, the opportunities for the patient will include factors such as the type of available market services, the level of service prices, the number and variety of medical units on the market, the medical unit location, the type of contact channels with the unit, and the information available on the market (both formal and informal). From the point of view of a medical unit, these opportunities represent the available means and tools of service provision, legal and organizational solutions, new technologies, and patient potential [35].

The present model plays a significant role in stimulating and shaping healthcare market entity relations. If any of the factors are not favorable or their combination is unattractive for the patients in a medical unit, then engagement in the relation is more likely not to occur than occur, even in a limited scope. The described model also places emphasis on the negative effects of the interactions between determinants, such as the negative associations with a given medical unit (motivation), the misunderstanding of a message conveyed by a medical unit representative (abilities), and the wrong choice of a patient segment (opportunities). Each of these factors is composed of many variables that create "a bunch", which acts as a motivator for the subject's engagement in a relation, proves subject's abilities, and creates conditions that enable involvement in these relations [35].

\section{Materials and Methods}

When attempting to identify the determinants of the relationship between patients and healthcare organizations in the medical services market in a virtual environment, one should remember that the degree of implementation of virtual instruments for the provision of medical services remains very limited. Although the application of virtual communication tools is becoming more common, in comparison to other markets, including the banking services market, the virtualization of the health sector is in its initial stages. Therefore, it was necessary in this study to investigate the attitudes of patients towards the medical services market considering service provisions and mutual communication and, consequently, engagement in their definite market relations with healthcare organizations in the virtual environment. In practice, patients were asked about the motivations that could make them engaged in certain relations with healthcare organizations in the virtual environment. Furthermore patients were requested to define their abilities that could be indispensable for the development of virtual relations and to assess their opportunities for engagement in these relations under the current stage of virtualization.

To investigate patients' determinants of their relationship with healthcare organizations in a virtual environment, direct quantitative research was conducted on a nationwide scale. In practice, the purpose of this research was to determine patients' attitudes towards their relationships with healthcare organizations, which, in turn, allowed us to build a model of the patient-healthcare organization relationship in a virtual environment. Direct research was conducted in Poland using the online survey method by means of a questionnaire in 2020. The size of the sample group was selected for this sectorial research based on the recommendations by Keedzior and Karcz [44] and Karcz [45]. Research was done only among patients from medical units in Poland. The structure of the sample group and that of the population of Internet users was identical. To develop a proper sample of the respondents, the quota sampling method was applied. The quotas were the genders and ages of the respondents. A systematic analysis was used to assess the collected empirical material (starting from formulating the research problem, through to interpretation and the presentation of suggestions for action). The research results were subjected to a statistical analysis using the SPSS software for Windows. 
As a result of verifying the correctness and reliability of the collected material, 256 questionnaires were ultimately analyzed. The research sample included $133(52 \%)$ women and $123(48 \%)$ men. Respondent ages were distributed as follows: $50(19,5 \%)$ were $18-24$ years old; $54(21,1 \%)$ were 26-35 years old, $52(20,3 \%)$ were $36-45$ years old, $50(19,5 \%)$ were $46-55$ years old, and $50(19,5 \%)$ were 56 years old and above. Apart from these characteristics, the level of education, size of the household, place of living, and economic situation were taken into consideration.

The main part of the survey questionnaire includes a question in the form of a Likert-type scale used for the construction of the patient-healthcare organization relationship model in a virtual environment. The question was based on a three factor (3F) model of consumer behavior, considering motivation, capacity, and opportunities, under the assumption that before deciding upon some definite behaviors (e.g., the patients make a decision about involvement in their relationship with healthcare organizations using virtual instruments), the consumer defines his/her motivations and assesses his/ her capacity and external possibilities. It is presumed, however, that these assessments require some, albeit minimal, intellectual and time engagement on the part of the consumer [37]. In the 3F model, it is assumed that all factors that determine consumer behavior in the market can be reduced to three major determinants. With this level of generalization, a more detailed analysis of various determinants seems unnecessary. The three main determinants can also affect (influence) one another when, for example, a low level of opportunity perceived by a consumer rules out that consumer's high motivation to become involved in a particular behavior. In the case of insufficient motivation, the consumer, on the other hand, cannot be encouraged to make a purchase in the market, despite a high level of capacity and opportunities [40]. A combination of the determinants (motivation, capacity, and opportunities) can be analyzed either with a high degree of generalization (not depending on the product, brand, etc.) or in great detail (depending on the product, brand, etc.). Given the choice of various determinants, the consumer is expected to develop and demonstrate certain behavior in the market (the consumer considers the most appropriate variables included in the $3 \mathrm{~F}$ model).

\section{Results and Discussion}

\subsection{Determinants of Patient Engagement with Healthcare Units in a Virtual Environment}

Direct research shows that patients' relationships with healthcare organizations in a virtual environment are determined by factors with different characteristics and scales of influence. In practice, patients are motivated to engage in relationships with their healthcare organizations via virtual tools mostly on the recommendation of their friends or due to legal obligations (Table 1).

Table 1. Analysis of the means for the motivation factor.

\begin{tabular}{cc}
\hline Question Number & Mean \\
\hline Q7 & 2.2 \\
Q10 & 1.9 \\
Q11 & 2.2 \\
Q13 & 3.0 \\
Q14 & 3.6 \\
Q15 & 2.0 \\
Q21 & 2.1 \\
\hline
\end{tabular}

Research shows that motivations with a social character (apart from friends (3.6 points)) and the recommendations of doctors or other employees from healthcare organizations (2.1 points) play significant roles in patients' decisions in the virtual medical services market. Another factor that healthcare organizations can influence is marketing ( 2.2 points). It should be underlined that factors with an organizational character, such as attractive infrastructure ( 2.0 points) and the efficiency (1.9 points) of medical service delivery, play a relatively minimal role for patients. 
In the respondents' opinion, the most important capacities of patients on the virtual medical services market are those connected to wide knowledge of specific features of medical services. This knowledge is important because it allows one to make fast, independent decisions to reduce the risk in using virtual healthcare services (Table 2).

Table 2. Analysis of the means for the capacity factor.

\begin{tabular}{cc}
\hline Question Number & Mean \\
\hline Q3 & 2.4 \\
Q4 & 3.1 \\
Q8 & 2.9 \\
Q16 & 2.7 \\
Q17 & 2.1 \\
Q18 & 2.9 \\
Q19 & 2.8 \\
\hline
\end{tabular}

Notably, trust (only 2.1 points) does not play a more important role in patients' decisions on the medical services market. Previous patients' experience with traditional healthcare organizations and their developed trust for these organizations can also be transferred to virtual healthcare organizations. Further, the ability to use Internet tools ( 2.4 points) and purchase different services online ( 2.7 points) are no longer an issue. However, because this research was done online, the respondents were required to have Internet skills. Research also shows that healthcare organizations, to build long-term relationships in the virtual environment, should focus mostly on giving patients all possible ways to contact the medical unit, including virtual channels, to stay safe. They also believe that high competition in the market is conducive to the use of virtual health services (Table 3).

Table 3. Analysis of the means for the opportunity factor.

\begin{tabular}{cc}
\hline Question Number & Mean \\
\hline Q1 & 1.9 \\
Q2 & 1.8 \\
Q5 & 2.6 \\
Q6 & 2.5 \\
Q9 & 2.1 \\
Q12 & 2.2 \\
Q20 & 2.2 \\
\hline
\end{tabular}

Analysis shows that financial aspects are not important for patients on the virtual medical market (only 1.8 points) as a factor influencing their tendency to use online services. Likewise, accessibility (1.9 points) to virtual services and widely available information about these services did not create opportunities for patients on the virtual medical services market.

\subsection{Patient-Healthcare Organizations Relationship Model in Virtual Environment}

To build a model for the patient-healthcare organization relationship in a virtual environment, exploratory factor analysis was applied. Factor analysis is used to detect the hidden, unobservable structures formed by variables. It also confirms the multidimensionality of a data set and is the basis for confirmatory factor analysis, which, in turn, is the basis of structural equation models. The use of Varimax orthogonal rotation allows the creation of uncorrelated factors, while oblique rotation (e.g., oblimin) creates nonorthogonal factors, i.e., those whose correlation coefficients are different from zero. The use of orthogonal rotation allows for the easier interpretation of factors than oblique rotation. Oblique factors have a less obvious meaning, which is why they are less common. We adopted the use of independent factors, where every factor explains an individual and specific element in the model. Hence, we chose varimax orthogonal rotation. 
This method allowed us to identify the factors describing the relations between subjects on the medical services market, with variables simultaneously constituting the basis for model development. Factor analysis and the modeling of structural equations were carried out for a set of 21 questions measured on a five-point Likert scale. The set of questions is presented in Table 4.

Table 4. The set of questions.

\begin{tabular}{|c|c|}
\hline No & Question \\
\hline Q_1 & $\begin{array}{l}\text { The continuous provision of health services via the Internet and their availability } 24 \mathrm{~h} \text { a day is } \\
\text { conducive to using such services. }\end{array}$ \\
\hline Q_2 & I will use virtual health services if they are free. \\
\hline Q_3 & To use virtual health services, you need to have knowledge of electronic tools at an appropriate level. \\
\hline Q_4 & There is a high risk in using virtual health services. \\
\hline Q_5 & $\begin{array}{l}\text { You should protect yourself and use all possible ways to contact the medical unit, including virtual } \\
\text { channels. }\end{array}$ \\
\hline Q_6 & The presence of high competition in the market is conducive to the use of virtual health services. \\
\hline Q_7 & Attractive forms of promotion used by medical units may lead me to use virtual health services. \\
\hline Q_8 & $\begin{array}{l}\text { To use virtual health services, you need to be very knowledgeable about the health services } \\
\text { themselves. }\end{array}$ \\
\hline Q_9 & Broad and accessible information about virtual health services is conducive to using these services. \\
\hline Q_10 & I can be encouraged by the speed of service provision to use virtual health services. \\
\hline Q_11 & $\begin{array}{l}\text { I would be inclined to use virtual health services for a chronic illness or due to other needs for } \\
\text { constant contact with a medical unit. }\end{array}$ \\
\hline Q_12 & A wide range of virtual health services is more conducive to using these services. \\
\hline Q_13 & I would use virtual health services if my friends also used them. \\
\hline Q_14 & Only legal obligations would force me to use virtual health services. \\
\hline Q_15 & I would be prompted by the ease of accessing the services to use virtual health services. \\
\hline Q_16 & $\begin{array}{l}\text { To use virtual health services, you need to have extensive experience in using various types of services } \\
\text { over the Internet. }\end{array}$ \\
\hline Q_17 & To use virtual health services, you need a high level of trust in a given medical unit. \\
\hline Q_18 & To use virtual health services, you must be able to make decisions quickly. \\
\hline Q_19 & The use of virtual health services requires great independence. \\
\hline Q_20 & Various virtual channels for contacting medical units favor the use of virtual health services. \\
\hline Q_21 & $\begin{array}{l}\text { The appropriate recommendations of an employee of a medical unit / doctor would prompt me to use } \\
\text { virtual health services. }\end{array}$ \\
\hline
\end{tabular}

The following assumptions were adopted in the factor analysis:

- Value of the KMO sample adequacy test: a minimum of 0.7;

- Method: main components;

- Extraction: fixed number of factors, 3;

- Rotation method: varimax orthogonal;

- Factor load level: a minimum absolute value of 0.5.

The KMO test result for sample adequacy was 0.783 , which is satisfactory and justifies the factor analysis. The Bartlett's sphericity test result for verifying the hypothesis that the correlation matrix between variables (questions) was unitary, indicating the need to reject this hypothesis (Chi-square: 1312.03, degrees of freedom: 210, significance: 0.000 ). Thus, a hidden factor structure is expected within the analyzed variables. 
Factor analysis allowed us to isolate three independent factors, which, together, explained $40.83 \%$ of the variability of the input data set of 21 questions. However, some of the questions showed low factor loadings on each of the factors, so these questions were removed from further analysis. The final set contained 17 questions.

The level of the total explained variance after removing four questions from the input data set (for which the absolute value of factor loadings was below the level of 0.5) is presented in Table 5.

Table 5. Total explained variance.

\begin{tabular}{|c|c|c|c|c|c|c|c|c|c|}
\hline \multirow{2}{*}{ Component } & \multicolumn{3}{|c|}{ Initial Eigenvalues } & \multicolumn{3}{|c|}{$\begin{array}{l}\text { Extraction Sums of Squared } \\
\text { Loadings }\end{array}$} & \multicolumn{3}{|c|}{$\begin{array}{c}\text { Rotation Sums of Squared } \\
\text { Loadings }\end{array}$} \\
\hline & Total & $\begin{array}{c}\% \\
\text { Variance }\end{array}$ & $\begin{array}{c}\% \\
\text { Cumulative }\end{array}$ & Total & $\begin{array}{c}\% \\
\text { Variance }\end{array}$ & $\begin{array}{c}\% \\
\text { Cumulative }\end{array}$ & Total & $\begin{array}{c}\% \\
\text { Variance }\end{array}$ & $\begin{array}{c}\% \\
\text { Cumulative }\end{array}$ \\
\hline 1 & 4.041 & 23.770 & 23.770 & 4.041 & 23.770 & 23.770 & 3.232 & 19.010 & 19.010 \\
\hline 2 & 2.448 & 14.402 & 38.172 & 2.448 & 14.402 & 38.172 & 2.681 & 15.770 & 34.780 \\
\hline 3 & 1.348 & 7.932 & 46.104 & 1.348 & 7.932 & 46.104 & 1.925 & 11.324 & 46.104 \\
\hline 4 & 1.108 & 6.518 & 52.622 & & & & & & \\
\hline 5 & 0.979 & 5.757 & 58.379 & & & & & & \\
\hline 6 & 0.914 & 5.376 & 63.755 & & & & & & \\
\hline 7 & 0.881 & 5.184 & 68.939 & & & & & & \\
\hline 8 & 0.732 & 4.308 & 73.248 & & & & & & \\
\hline 9 & 0.706 & 4.153 & 77.401 & & & & & & \\
\hline 10 & 0.633 & 3.724 & 81.125 & & & & & & \\
\hline 11 & 0.607 & 3.573 & 84.698 & & & & & & \\
\hline 12 & 0.545 & 3.205 & 87.903 & & & & & & \\
\hline 13 & 0.457 & 2.688 & 90.592 & & & & & & \\
\hline 14 & 0.444 & 2.611 & 93.203 & & & & & & \\
\hline 15 & 0.420 & 2.469 & 95.672 & & & & & & \\
\hline 16 & 0.399 & 2.349 & 98.021 & & & & & & \\
\hline 17 & 0.336 & 1.979 & 100.000 & & & & & & \\
\hline
\end{tabular}

The factor analysis identified three independent factors that together explained $46.1 \%$ of the input data set. The matrix of factors after applying varimax orthogonal rotation is presented in Table 6.

Table 6. Matrix of rotated factors.

\begin{tabular}{clc}
\hline Question & \multicolumn{1}{c}{ Description } & Factor \\
\hline 10 & $\begin{array}{l}\text { I can be encouraged by the speed of service provision to use virtual } \\
\text { health services. }\end{array}$ & 0.711 \\
\hline 9 & $\begin{array}{l}\text { Broad and accessible information about virtual health services is } \\
\text { conducive to using these services. }\end{array}$ & 0.680 \\
\hline 20 & $\begin{array}{l}\text { Various virtual channels for contacting medical units favor the use of } \\
\text { virtual health services. }\end{array}$ & 0.659 \\
\hline 21 & $\begin{array}{l}\text { The appropriate recommendations of an employee of a medical } \\
\text { unit/doctor would prompt me to use virtual health services. }\end{array}$ & 0.636 \\
\hline 15 & $\begin{array}{l}\text { I would be prompted by the ease of accessing virtual health services } \\
\text { to use such services. }\end{array}$ \\
\hline 12 & $\begin{array}{l}\text { A wide range of available virtual health services is more conducive to } \\
\text { using these services. }\end{array}$ \\
\hline
\end{tabular}


Table 6. Cont.

\begin{tabular}{|c|c|c|c|c|}
\hline \multirow{2}{*}{ Question } & \multirow{2}{*}{ Description } & \multicolumn{3}{|c|}{ Factor } \\
\hline & & 1 & 2 & 3 \\
\hline 11 & $\begin{array}{l}\text { I would be inclined to use virtual health services for a chronic illness } \\
\text { or due to other needs for constant contact with a medical unit. }\end{array}$ & 0.521 & & \\
\hline 4 & There is a high risk in using virtual health services. & & 0.729 & \\
\hline 8 & $\begin{array}{l}\text { To use virtual health services, you need to be very knowledgeable } \\
\text { about the health services themselves. }\end{array}$ & & 0.658 & \\
\hline 18 & $\begin{array}{l}\text { To use virtual health services, you must be able to make decisions } \\
\text { quickly. }\end{array}$ & & 0.637 & \\
\hline 19 & The use of virtual health services requires great independence. & & 0.565 & \\
\hline 16 & $\begin{array}{l}\text { To use virtual health services, you need to have extensive experience } \\
\text { in using various types of services over the Internet. }\end{array}$ & & 0.548 & \\
\hline 5 & $\begin{array}{l}\text { You should protect yourself and use all possible ways to contact the } \\
\text { medical unit, including virtual channels. }\end{array}$ & & 0.536 & \\
\hline 13 & I would use virtual health services if my friends also used them. & & 0.509 & \\
\hline 2 & I will use virtual health services if they are free. & & & 0.774 \\
\hline 1 & $\begin{array}{l}\text { The continuous provision of health services via the Internet and their } \\
\text { availability } 24 \mathrm{~h} \text { a day is conducive to using such services. }\end{array}$ & & & 0.744 \\
\hline 7 & $\begin{array}{l}\text { Attractive terms of promotion used by medical units may lead me to } \\
\text { use virtual health services. }\end{array}$ & & & 0.574 \\
\hline
\end{tabular}

The method of extracting factors-the main components. Rotation method-varimax with Kaiser normalization. Rotation achieved convergence in 5 iterations.

The factors thus created were then used to provide a model for structural equations. When estimating the model parameters, the following assumptions were made:

- Estimation of discrepancies between the theoretical construct and empirical model using the maximum likelihood method;

- Estimation of the covariance matrix by the maximum likelihood method;

- Modification index specifying the degree of correlation of a random component at level 10 (this means that the model includes the correlations of random components for which the modification index exceeds level 10).

The model parameters are presented in Table 7.

Table 7. Model parameters.

\begin{tabular}{cllccccc}
\hline & \multirow{2}{*}{ Relation } & $\begin{array}{c}\text { Coefficient } \\
\text { Regression }\end{array}$ & $\begin{array}{c}\text { Coefficient } \\
\text { Standardized Beta }\end{array}$ & $\begin{array}{c}\text { Standard } \\
\text { Error }\end{array}$ & $\begin{array}{c}\text { Critical } \\
\text { Value }\end{array}$ & Sig. \\
\hline Q_10 & $<-$ & Motivation & 1.000 & 0.720 & - & - & - \\
Q_9 & $<-$ & Motivation & 0.727 & 0.551 & 0.091 & 7.984 & $<0.001$ \\
Q_20 & $<-$ & Motivation & 0.685 & 0.571 & 0.085 & 8.014 & $<0.001$ \\
Q_21 & $<-$ & Motivation & 0.718 & 0.552 & 0.088 & 8.174 & $<0.001$ \\
Q_15 & $<-$ & Motivation & 0.815 & 0.674 & 0.087 & 9.413 & $<0.001$ \\
Q_12 & $<-$ & Motivation & 0.599 & 0.449 & 0.096 & 6.264 & $<0.001$ \\
Q_11 & $<-$ & Motivation & 0.606 & 0.381 & 0.107 & 5.645 & $<0.001$ \\
Q_13 & $<-$ & Capacity & 1.000 & 0.433 & - & - & - \\
Q_5 & $<-$ & Capacity & 1.303 & 0.533 & 0.253 & 5.153 & $<0.001$ \\
Q_16 & $<-$ & Capacity & 0.907 & 0.430 & 0.200 & 4.529 & $<0.001$ \\
\hline
\end{tabular}


Table 7. Cont

\begin{tabular}{clcccccc}
\hline & \multirow{2}{*}{ Relation } & $\begin{array}{c}\text { Coefficient } \\
\text { Regression }\end{array}$ & $\begin{array}{c}\text { Coefficient } \\
\text { Standardized Beta }\end{array}$ & $\begin{array}{c}\text { Standard } \\
\text { Error }\end{array}$ & $\begin{array}{c}\text { Critical } \\
\text { Value }\end{array}$ & Sig. \\
\hline Q_19 & $<-$ & Capacity & 0.984 & 0.471 & 0.207 & 4.757 & $<0.001$ \\
Q_18 & $<-$ & Capacity & 1.097 & 0.497 & 0.217 & 5.043 & $<0.001$ \\
Q_8 & $<-$ & Capacity & 1.349 & 0.617 & 0.251 & 5.378 & $<0.001$ \\
Q_4 & $<-$ & Capacity & 1.479 & 0.640 & 0.277 & 5.346 & $<0.001$ \\
Q_2 & $<-$ & Opportunity & 1.000 & 0.582 & - & - & - \\
Q_1 & $<-$ & Opportunity & 1.05 & 0.657 & 0.163 & 6.434 & $<0.001$ \\
Q_7 & $<-$ & Opportunity & 1.07 & 0.531 & 0.197 & 5.444 & $<0.001$ \\
\hline
\end{tabular}

The results show that all relationships are statistically significant. A positive and moderately strong effect was observed. Factor 1 (motivation; the impact strength measured by standardized beta) answered questions 10 and 15 most strongly, factor 2 (capacity) answered questions 4 and 8 , while factor 3 (opportunity) answered question 1 . This is a correlational model whose parameters are presented in Table 8.

Table 8. Parameters of the correlational model.

\begin{tabular}{cccccccc}
\hline & \multirow{2}{*}{ Relation } & & Covariance & $\begin{array}{c}\text { Standard } \\
\text { Error }\end{array}$ & Correlation & $\begin{array}{c}\text { Critical } \\
\text { Value }\end{array}$ & Sig. \\
\hline Motivation & $<->$ & Opportunity & 0.227 & 0.042 & 0.619 & 5.467 & $<0.001$ \\
\hline Capacity & $<->$ & Opportunity & 0.060 & 0.027 & 0.226 & 2.182 & $0.029^{*}$ \\
\hline Motivation & $<->$ & Capacity & 0.049 & 0.033 & 0.139 & 1.499 & 0.134 \\
\hline \multicolumn{7}{c}{ * Significant at a level of 0.05.} &
\end{tabular}

The results show that all factors are related, and their relationships are positive. The strongest relationship was observed between factors 1 (motivation) and 3 (opportunity), which was rated as moderately strong and positive (0.619). Factors 2 (capacity) and 3 (opportunity) are positively but weakly correlated $(0.226)$. However, no statistically significant correlation was observed between factor 1 (motivation) and 2 (capacity).

In the last stage of the theoretical model verification, the efficiency/fitness of the model was assessed. To this end, the following indicators were used:

- CMIN/df: quotient of the Chi-square index and the number of degrees of freedom; acceptable level of the measure indicating a good fit of the model: below 5.0;

- $\quad$ RMR: root of the mean square of residues; acceptable level of the measure indicating a good fitnessof the model: below 0.1 ;

- GFI: goodness-of-fit index; acceptable level of the measure demonstrating a good fitness of the model: above 0.9;

- AGFI: adjusted goodness-of-fit index; acceptable level of the measure demonstrating a good fitness of the model: above 0.9 ;

- CFI: relative match index; acceptable level of the measure demonstrating a good fitness of the model: above 0.9;

- RMSEA: root mean square approximation error; acceptable level of the measure demonstrating a good fitess of the model: below 0.08;

- PCLOSE: proximity indicator; acceptable level: above 0.05 .

Table 9 outlines these fitness measures. 
Table 9. Model fitness assessment.

\begin{tabular}{ccc}
\hline Goodness of Fitness Indicator & Value & Rating \\
\hline CMIN/df & 1.786 & Acceptable model \\
RMR & 0.064 & Acceptable model \\
GFI & 0.922 & Acceptable model \\
AGFI & 0.889 & Conditionally acceptable model \\
CFI & 0.910 & Acceptable model \\
RMSEA & 0.056 & Acceptable model \\
PCLOSE & 0.229 & Acceptable model \\
\hline
\end{tabular}

The fitness assessment results show that all measures except for AGFI fully agreed with the model. The result for AGFI was slightly different in the area of acceptability. It can, therefore, be concluded that this model correctly describes the actual structure of the variance-covariance matrix between the analyzed components of the construct. The final model has the form shown in Figure 2.

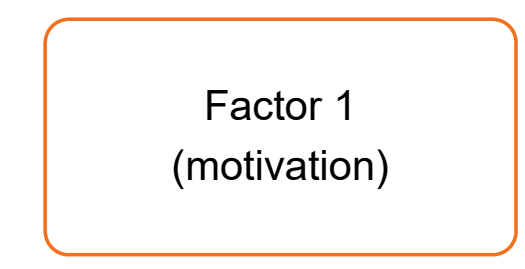

\subsection{3}

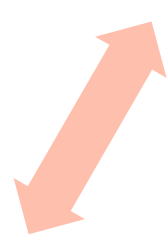

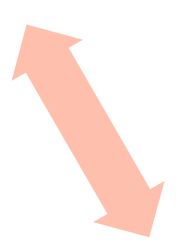

0.61
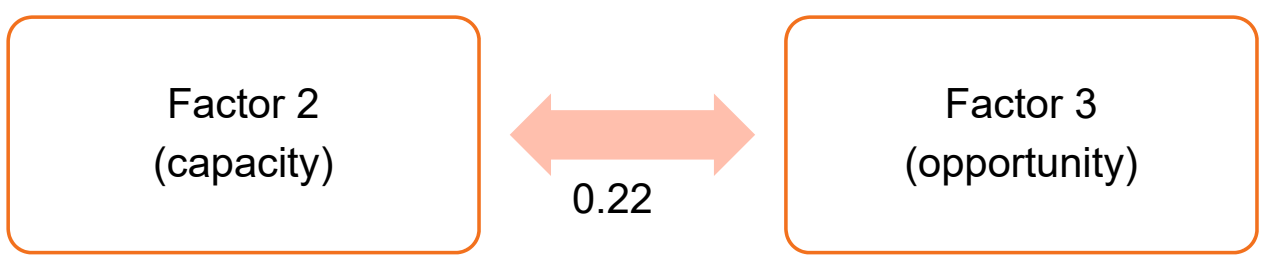

Figure 2. Three factor model of the relationship between patients and healthcare organizations in a virtual environment.

Based on the above analysis, patients' relationships with healthcare organizations in a virtual environment are shaped by three factors: the patient's ability to engage in a given relationship, the possibilities that the healthcare organizations create for their patients, and the motivation of the patients to engage in given relationships with healthcare organizations via virtual tools.

\section{Conclusions}

The present research shows that patients' attitudes toward engaging in relationships with healthcare organizations in virtual environments depend on the patients' motivation and the capacity, as well the virtual market opportunities. The most important motivation factors are recommendations from the patients' friends and legal obligations. If we consider capacities, it is worth noting the important role of knowledge about specific features of medical services and the ability to make fast, independent decisions to reduce the risk of using virtual healthcare services. Finally, healthcare 
organizations should focus on giving their patients all possible ways of contacting the medical unit, including contact via virtual channels, to stay safe.

Bearing in mind the above considerations, we cane also conclude that the factor analysis confirmed the examined models of the relationship of patients with healthcare organizations on the medical services market in a virtual environment. The presented measures of the models, except for AGFI, can be accepted. All indexes (selected on the basis of the exploratory factor analysis) were shown to be strongly related to the constructs they measured. Therefore, the relationships of patients with healthcare organizations in a virtual environment will develop provided that the patients are properly motivated and have adequate abilities to become engaged in such relations when market opportunities are favorable. Moreover, as shown by the exploratory factor analysis, a considerable role is played by patients' abilities in, and motivations towards, e-tool applications for medical service provisions and communication.

A word of caution: this research has some limitations. However, these limitations could be advantageous for future research. The key limitation of this study is its focus on only one market of healthcare services. The relations between consumers and companies, especially in the consumption goods, are certainly different and can affect the significance of the three selected factors defining the aforementioned relations. One should also emphasize that this research was conducted online. Patients' attitudes towards e-healthcare may differ for customers who do not use the Internet. Nonetheless, it is believed that focusing on different markets and analyzing these phenomena, not only in virtual areas but also in other environments, will contribute to a better understanding of the relationships between patients and healthcare units in the e-healthcare market. It would be also interesting to investigate the hypothesized models in other countries in order to generalize the results across cultures.

Author Contributions: Conceptualization, J.M. and S.S.; methodology and data analysis, J.M. and S.S.; writing - review and editing, J.M. and S.S. All authors have read and agreed to the published version of the manuscript.

Funding: This work was created as a result of the research project no.2011/01/B/HS4/07572 financed by the funds of the National Science Center.

Conflicts of Interest: The authors declare no conflict of interest.

\section{References}

1. Green, A.R.; Caarriillo, E.; Betancourt, J.R. Why the disease-based model of medicine fails our patients. West J. Med. 2002, 176, 141-143. [PubMed]

2. Lega, F.; de Pietro, C. Converging patterns in hospital organization: Beyond the professional bureaucracy. Health Policy 2005, 74, 261-281. [CrossRef]

3. Stewart, M. Towards a global definition of patient centred care. The patient should be the judge of patient entred care. BMJ 2001, 322, 444-445. [CrossRef] [PubMed]

4. Epstein, R.M.; Street, R.L. The value of patient-centred care. Patient Educ. Couns. 2007, 68, 179-185.

5. Huan, X.R.; Wai, A.; Cheung, L.; Lai, E.; Wong, Y. The relationship between patient engagement and health-related quality of life in patients: A cross-sectional study in general outpatient clinic in Hong Kong SAR, China. Patient Prefer. Adherence 2019, 13, 1451-1462.

6. NEJM Catalyst Innovations in Care Delivery. What Is Patient-Centered Care? January 2007. Available online: https://catalyst.nejm.org/doi/full/10.1056/CAT.17.0559 (accessed on 2 May 2020).

7. Marovino, T. Technology Changing the Delivery of Healthcare, Practical Pain Management, 2017, Volume 16, Issue \#5. Available online: https://www.practicalpainmanagement.com/treatments/rehabilitation/technologychanging-delivery-healthcare (accessed on 5 May 2020).

8. Patient Experience in Adult NHS Services: Improving the Experience of Care for People Using Adult NHS Services: Patient Experience in Generic Terms. National Clinical Guideline Centre (UK), Royal College of Physicians (UK); February 2012. Available online: https://www.ncbi.nlm.nih.gov/books/NBK115233/ (accessed on 5 May 2020).

9. Vargo, S.L.; Lusch, R.F. Evolving to a New Dominant Logic. J. Mark. 2004, 68, 1-17. [CrossRef] 
10. Vargo, S.L.; Lusch, R.F. Service-dominant logic: Continuing the evolution. J. Acad. Mark. Sci. 2008, 36, 1-10. [CrossRef]

11. Spohrer, J.; Maglio, P.P.; Bailey, J.; Gruhl, D. Steps toward a Science of Service Systems. Computer 2007, 40, 71-77. [CrossRef]

12. Spohrer, J.; Maglio, P.P. The Emergence of Service Science: Toward Systematic Service Innovations to Accelerate Co-Creation of Value. Prod. Oper. Manag. 2008, 17, 238-246. [CrossRef]

13. Vargo, S.L.; Lusch, R.F. Service-dominant logic 2025. Int. J. Res. Mark. 2017, 34, 46-67. [CrossRef]

14. Soriano, J.; Heitz, C.; Hutter, H.P.; Fernández, R.; Hierro, J.J.; Vogel, J.; Edmonds, A.; Bohnert, T.M. Internet of Services. In Evolution of Telecommunication Services; Springer: Berlin/Heidelberg, Germany, 2013; pp. $283-325$.

15. Osterwalder, A.; Pigneur, Y.; Bernarda, G.; Smith, A. Value Proposition Design: How to Create Products and Services Customers Want, 1st ed.; John Wiley \& Sons: Hobroken, NJ, USA, 2014.

16. Nieuwenhuis, B. Value proposition design and business modelling. In eHealth Research, Theory and Development: A Multi-Disciplinary Approach; VanGemert-Pijnen, L., Kelders, S.M., Kip, H., Sanderman, R., Eds.; Routledge: Oxford, NY, USA, 2018; pp. 187-206.

17. van Limburg, M.; van Gemert-Pijnen, J.E.; Nijland, N.; Ossebaard, H.C.; Hendrix, R.M.; Seydel, E.R. Why business modeling is crucial in the development ofeHealth technologies. J. Med. Internet Res. 2011. [CrossRef] [PubMed]

18. Swayne, L.E. The Internet of Things (IoT): A Marketing Perspective. Int. J. Comput. Eng. Res. (IJCER) 2017, 7, 51-57.

19. Intelligence, B.I. Here's How the Internet of Things Will Explode by 2020, Business Insider, 31 August 2016. Available online: http://www.businessinsider.com/iot-ecosystem-internet-of-things-forecasts-and-businessopportunities-2016-2 (accessed on 5 May 2020).

20. Vermesan, O.; Friess, P.; Guillemin, P.; Gusmeroli, S.; Sundmaker, H.; Bassi, A.; Jubert, I.C.; Mazura, M.; Harrison, M.; Eisenhauer, M.; et al. Internet of Things Strategic Research Agenda. In Internet of ThingsGlobal Technological and Societal Trends; Denmark River Publishers: Aalborg, Denmark, 2011.

21. Terzidis, O.; Oberle, D.; Kadne, K. The Internet of Services and USDL. In Handbook of Service Description: USDL and its Methods; Barros, A., Oberle, D., Eds.; Springer Science and Business Media: New York, NY, USA, 2012; pp. 1-16.

22. Brodie, R.J.; Hollebeek, L.D.; Juric, B.; Ilic', A. Customer Engagement: Conceptual Domain, Fundamental Propositions, and Implications for Research. J. Serv. Res. 2011, 14, 252-271. [CrossRef]

23. Hollebeek, L.D. Individual-level cultural consumer engagement styles: Conceptualization, propositions and implications. Int. Mark. Rev. 2018, 35, 42-71. [CrossRef]

24. Bijmolt, T.H.A.; Leeflang, P.S.H.; Block, F.; Eisenbeiss, M.; Hardie, B.G.S.; Lemmens, A.; Saffert, P. Analytics for customer engagement. J. Serv. Res. 2010, 13, 341-356. [CrossRef]

25. Jaakkola, E.; Alexander, M. The role of customer engagement behavior in value co-creation: A service system perspective. J. Serv. Res. 2014, 17, 24. [CrossRef]

26. O'Meara, W.P.; Tsofa, B.; Molyneux, S.; Goodman, C.; Mckenzie, F.E. Community and facility-level engagement in planning and budgeting for the government health sector-A district perspective from Kenya. Health Policy 2011, 99, 234-243. [CrossRef]

27. Hibbard, J.H.; Greene, J. What the evidence shows about patient activation: Better health outcomes and care experiences; fewer data on costs. Health Aff. (Millwood) 2013, 32, 207-214. [CrossRef]

28. Patient Engagement. Technical Series on Safer Primary Care; WHO: Geneva, Switzerland, 2016.

29. Vahdat, S.; Hamzehgardeshi, L.; Hessam, S.; Hamzehgardesh, Z. Patient Involvement in Health Care Decision Making: A Review. Iran. Red Crescent Med. J. 2014, 16, e12454. [CrossRef]

30. Patient Engagement: How Patient-provider Partnerships Transform Healthcare Organisations; Pomey, M.P.; Denis, J.L.; Dumez, V. (Eds.) Palgrave Macmillan: Cham, Switzerland, 2019.

31. Hollebeek, L.D.; Glynn, M.; Brodie, R.J. Consumer Brand Engagement in Social Media: Conceptualization, Scale Development and Validation. J. Interact. Mark. 2014, 28, 149-165. [CrossRef]

32. Zaichkowsky, J.L. Conceptualizing involvement. J. Advert. 1986, 15, 4-14, 34. [CrossRef]

33. Guthrie, M.F.; Kim, H.-S. The relationship between consumer involvement and brand perceptions of female cosmetic consumers. J. Brand Manag. 2019, 17, 114-133. [CrossRef]

34. Liberati, E.G.; Gorli, M.; Scaratti, G. Reorganising hospitals to implement a patient-centered model of care. J. Health Organ Manag. Bradford 2015, 29, 848-873. [CrossRef] 
35. Matysiewicz, J.; Smyczek, S. Patients-medical unit relationship models in the virtual environment. EuroMed J. Bus. 2015, 8. [CrossRef]

36. Poiesz, T.B.C.; Robben, H.S.J. Individual Reactions to Advertising: Theoretical and Methodological Developments. Int. J. Advert. 1997, 2, 25-53. [CrossRef]

37. Smyczek, S. Modele Zachowań Konsumentów na Rynku Ustug Finansowych; Akademia Ekonomiczna w Katowicach: Katowice, Poland, 2007.

38. Petty, R.E.; Cacioppo, J.T. The effects of involvement on responses to argument quantity and quality: Central and peripheral routes to persuasion. J. Personal. Soc. Psychol. 1984, 46, 69-81. [CrossRef]

39. MacInnis, D.J.; Moorman, C.; Jaworski, B.J. Enhancing and measuring consumers' motivation, opportunity, and ability to process brand information from ads. J. Mark. 1991, 55, 32-53. [CrossRef]

40. Antonides, G.; van Raaij, W.F. Consumer behavior. European Perspective; John Wiley \& Sons, Ltd.: New York, NY, USA, 2003.

41. Mcshane, S.L.; von Glinow, M.A.; Sharma, R. Organizational Behavior; NTata McGraw-Hill Education: New Dehli, India, 2008.

42. Blackwell, R.D.; Miniard, P.W.; Engel, J.F. Consumer Behaviour; Dryden: Fort Worth, TX, USA, 2001.

43. Latusek, A. Praktyczny Słownik Wyrazów i Zwrotów Bliskoznacznych; Zielona Sowa: Kraków, Poland, 2001.

44. Kędzior, Z.; Karcz, K. Badania Marketingowe w Praktyce; PWE: Warszawa, Poland, 2007.

45. Karcz, K. Międzynarodowe Badania Marketingowe; PWE: Warszawa, Poland, 2004.

(C) 2020 by the authors. Licensee MDPI, Basel, Switzerland. This article is an open access article distributed under the terms and conditions of the Creative Commons Attribution (CC BY) license (http://creativecommons.org/licenses/by/4.0/). 